4 Schuyler B. Gentry ${ }^{1 \# a}$, Scott J. Nowak ${ }^{1}$, Xuelei Ni², Stephanie A. Hill ${ }^{1}$, Lydia R. Wade ${ }^{1}$, William

$5 \quad$ R. Clark ${ }^{1}$, Aidan P. Keelaghan ${ }^{1 \# b}$, Daniel P. Morris ${ }^{1}$ and Jonathan L. McMurry*1

$7{ }^{1}$ Department of Molecular \& Cellular Biology, Kennesaw State University, Kennesaw, Georgia, $8 \quad$ United States of America

$10{ }^{2}$ School of Data Science \& Analytics, Kennesaw State University, Kennesaw, Georgia, United

11 States of America

12

13 \#a Current Address: Q2 Solutions, Atlanta, Georgia, United States of America

14 \#b Current Address: Emory University School of Medicine, Atlanta, Georgia, United States of

15 America

16

$17 *$ Corresponding author

18 E-mail jmcmurr1@kennesaw.edu (JM) 
20 Abstract

Cell-penetrating peptides (CPPs) are capable of transporting molecules to which they are

22 tethered across cellular membranes. Unsurprisingly, CPPs have attracted attention for their

23 potential drug delivery applications, but several technical hurdles remain to be overcome. Chief

24 among them is the so-called 'endosomal escape problem,' i.e. the propensity of CPP-cargo

25 molecules to be endocytosed but remain entrapped in endosomes rather than reaching the cytosol.

26 Previously, a CPP fused to calmodulin that bound calmodulin binding site-containing cargos was

27 shown to efficiently deliver cargos to the cytoplasm, effectively overcoming the endosomal escape

28 problem. The CPP-adaptor, "TAT-CaM," evinces delivery at nM concentrations and more rapidly

29 than we had previously been able to measure. To better understand the kinetics and mechanism of

30 CPP-adaptor-mediated cargo delivery, a real-time cell penetrating assay was developed in which

31 a flow chamber containing cultured cells was installed on the stage of a confocal microscope to

32 allow for observation ab initio. Also examined in this study was an improved CPP-adaptor that

33 utilizes naked mole rat (Heterocephalus glaber) calmodulin in place of human and results in

34 superior internalization, likely due to its lesser net negative charge. Adaptor-cargo complexes were

35 delivered into the flow chamber and fluorescence intensity in the midpoint of baby hamster kidney

36 cells was measured as a function of time. Delivery of $400 \mathrm{nM}$ cargo was observed within seven

37 minutes and fluorescence continued to increase linearly as a function of time. Cargo-only control

38 experiments showed that the minimal uptake which occurred independently of the CPP-adaptor

39 resulted in punctate localization consistent with endosomal entrapment. A distance analysis was

40 performed for cell-penetration experiments in which CPP-adaptor-delivered cargo showing wider

41 dispersions throughout cells as compared to an analogous covalently-bound CPP-cargo. Small

42 molecule endocytosis inhibitors did not have significant effects upon delivery. The real-time assay 
bioRxiv preprint doi: https://doi.org/10.1101/2021.07.23.453555; this version posted July 23, 2021. The copyright holder for this preprint (which was not certified by peer review) is the author/funder, who has granted bioRxiv a license to display the preprint in perpetuity. It is made available under aCC-BY 4.0 International license.

43 is an improvement upon static endpoint assays and should be informative in a broad array of

\section{4 applications.}

45 


\section{Introduction}

48 frequent causes are failure to cross cell membranes and traffic to appropriate subcellular

49 destinations. Cell-penetrating peptides (CPPs) have long held great promise for transmembrane

50 delivery of therapeutics precisely because they can overcome these problems [1-4]. They catalyze

51 transmembrane passage of a wide variety of biomolecules with vastly different physicochemical

52 characteristics from large, oligomeric proteins to nucleic acids and small molecules. Generally, if

53 a molecule (the 'cargo') can be fused to a CPP, it can be delivered into a cell. CPP-containing

54 molecules are rapidly taken up by a wide array of eukaryotic cell types. Though dozens of clinical

55 trials are underway $[3,5]$, development of CPP-based therapeutics has been hampered several

56 vexing problems including toxicity at high doses currently required, a lack of ability to target

57 specific cells and covalent or otherwise irreversible CPP-cargo linkages that result in entrapment

58 in endosomes, the so-called 'endosomal escape problem' [6]. No CPP-based therapeutics have yet

59 been approved and several clinical trials have been terminated, but hope springs eternal and recent

60 advances have been made to address the technical hurdles yet to be overcome $[7,8]$.

61 Most CPP delivery schemes utilize irreversible linkages to cargo, usually covalent,

62 otherwise nonspecific or hydrophobic [9]. We previously reported the development and

63 application of CPP-tagged adaptor proteins with reversible noncovalent, $\mathrm{Ca}^{2+}$-dependent couplings

64 that enable cargos to be transported into cells and then released from the CPP [10, 11]. Our lead

65 adaptor, TAT-CaM, consists of the cell-penetrating moiety of HIV transactivator of transcription

66 (TAT) N-terminally fused to human calmodulin (CaM). Cargo proteins are recombinant fusions

67 containing a 17-residue calmodulin binding site (CBS). TAT-CaM/CBS-cargo complexes

68 spontaneously bind with $\mathrm{nM}$ affinity in the presence of $\mathrm{Ca}^{2+}$, but negligibly in its absence. Changes 
69 in $\left[\mathrm{Ca}^{2+}\right]$ and $\mathrm{pH}$ after internalization [8] result in release of cargo. We have shown that numerous

70 cargos reach the cytoplasm or other subcellular destination in multiple cell lines once released

71 from the CPP-adaptor even though the CPP itself remains trapped in endosomes [9, 10], i.e. we

72 have solved the endosomal escape problem. Our technology gets cargo into cells and out of

73 endosomes into the cytoplasm even though the CPP itself, like others, remains trapped. Increased

74 escape efficiency may allow for lowering dosing. Other CPP-cargos must be present in $\mu \mathrm{M}$ or tens

75 of $\mu \mathrm{M}$ to observe cytoplasmic delivery whereas TAT-CaM achieves observable delivery at nM

76 concentrations.

77 Optimization of the CPP-EF-hand architecture of TAT-CaM and other adaptors has also

78 been a priority. It was previously reported that several other EF-hand proteins and several other

79 CPP moieties evinced no discernible difference in delivery of a model cargo [11], suggesting that

80 calmodulin was at least as effective as other EF hand proteins. In the present study, we examined

81 calmodulins from other species for qualities that would increase efficacy in delivery, finding that

82 naked mole rat (Heterocephalus glaber) calmodulin ("NMR-CaM") was more effective at

83 inducing internalization than human calmodulin. NMR-CaM varies from human in several

84 respects, most dramatically in molecular weight ( $\sim 30 \mathrm{kDa} v \mathrm{17} \mathrm{kDa})$ and net charge (-15 vs. -

85 24) but binds a human calmodulin binding moiety with similar affinity and kinetics. It has an

86 amino-terminal domain of unknown function lacking discernible homology to known sequences

87 from residues 1-128 but the rest is invariant from human calmodulin save the analogous position

88 of the initiating methionine, 129 , is a leucine in NMR-CaM.

A number of worthy efforts have been made to examine the kinetics of CPP-mediated cargo

90 delivery [12-17]. These studies were examinations of different CPPs in various cell lines under

91 different conditions, and they used various methods of detection that relied on analyzing whole 
92 cells, including radiometric and spectrophotometric assays, flow cytometry and conventional

93 fluorescence microscopy. While a few informative studies have been done using exotic techniques

94 that measured actual cytosolic delivery, e.g. ${ }^{19} \mathrm{~F}$ NMR [18], it has long been desirous to have a

95 relatively simple assay that analyzes delivery to cell interiors in living cells using readily labeled

96 cargos. In this study, we developed a real-time, live cell assay using commercially available

97 channel slides that allows cells to be cultured in a flow chamber so that direct imaging of cell

98 interiors during cargo delivery can be done using confocal microscopy. Using a peristaltic

99 pumping system, CPP-cargo complexes were applied to cells from a reservoir to effect subcellular

100 observation from time zero under buffered and temperature-controlled conditions.

We were interested not only in the kinetics of CPP-mediated delivery of cargo, but also in

102 better understanding how our CPP-adaptors' $\mathrm{Ca}^{2+}$-mediated release works inside the cell, which

103 required improving our static endpoint assay to be able to observe early time periods during the

104 course of delivery. Under conditions used in this study, TAT-NMR-CaM delivered a model cargo,

105 maltose binding protein, to the cytoplasm of baby hamster kidney (BHK) cells with observable

106 fluorescence in seven minutes. In contrast to some earlier work, delivery was linear over the course

107 of the assay, perhaps due to the much lower dosing our CPP-adaptors enable. Distance analysis of

108 delivery with comparison to an analogous covalently conjugated TAT-cargo protein showed less

109 punctate cellular distribution, consistent with enhanced endosomal escape. Addition of

110 endocytosis inhibitors was largely inconclusive, but treatment with caveolin-mediated

111 endocytosis, inhibitor methyl- $\beta$-cyclodextrin appeared to reduce delivery, though only at

112 substantially high concentrations that precluded strong conclusions. Future studies will examine

113 dosing, temperature and other parameters as well as other cargos, CPPs and endosomal escape

114 enhancers to better understand the mechanism and kinetics of delivery. 
Here we report the first real-time assay using direct observation of cargo delivery to the

116 cytoplasm of living cells by confocal microscopy. It is an improvement upon earlier kinetic assays

117 in that unlike conventional fluorescence microscopy, allows imaging at specific depths in the cell,

118 thus overcoming problems posed by potentially confounding artifacts such as surface adherence.

\section{Materials \& Methods}

Plasmids, strains and cell lines. Plasmids used were previously described $[10,11]$ or

122 constructed as described in Supporting Information. Briefly, pJM161 consisted of an E. coli-

123 optimized synthetic gene (GeneScript, Piscataway, NJ, USA) encoding TAT-naked mole rat

124 calmodulin (TAT-NMR-CaM) cloned into NdeI and BamHI sites in pET19b (EMD Millipore,

125 USA) with an in-frame stop codon prior to the BamHI site. The encoded TAT-NMR-CaM protein

126 consists of the TAT peptide sequence (YGRKKRRQRRR) N-terminally fused to Heterocephalus

127 glaber (naked mole rat) calmodulin (GenBank: EHB02604.1)[19]. A vector-encoded 10xHis tag

128 is N-terminal to TAT. Plasmids pJM140 and pJM168, encoding CBS-maltose binding protein

129 (CBS-MBP) and TAT-maltose binding protein (TAT-MBP), respectively, were made by cloning

130 synthetic gene fragments encoding the CBS or TAT peptide sequences into NdeI and BamHI sites

131 in pMAL-c5x (New England Biolabs, Ipswich, MA). The encoded cargo proteins thus have either

132 a CBS or TAT sequence C-terminal to the MBP and a 6x His tag beyond.

133 E. coli used in this study, BL21(DE3)pLysS was propagated from purchased cells from

134 EMD Millipore (Burlington, MA, USA) or other established supplier.

135 Baby hamster kidney (BHK) cells were purchased from ATCC (\#CCL-10) and cultured in

136 Dulbecco's Modified Eagles’ Medium with GlutaMAX Supplement (Gibco, USA) and 10\% fetal

137 bovine serum. 
Expression, purification and labeling. Proteins were expressed essentially as described

139 [20] with minor modifications. Briefly, plasmids were freshly transformed into BL21(DE3)pLysS.

140 Overnight cultures grown from single colonies were subcultured into 1L Luria-Bertani broth and

141 grown with vigorous shaking at $37^{\circ} \mathrm{C}$. At $\mathrm{OD}_{600} \sim 0.4$, temperature was lowered to $30^{\circ} \mathrm{C}$ and cells

142 were induced with $0.2 \mathrm{mM}$ IPTG and growth continued for four hours. The procedure was altered

143 slightly for CBS-MBP, which was grown in Terrific Broth (TB) supplemented with $0.25 \%(\mathrm{w} / \mathrm{v})$

144 glucose and induction was conducted at $32^{\circ} \mathrm{C}$. Cells were harvested by centrifugation at $10,000 \mathrm{x}$

$145 \mathrm{~g}$ and frozen at $-80^{\circ} \mathrm{C}$.

146 Purification was also performed essentially as described [15] via immobilized metal

147 affinity chromatography. Briefly, cell pellets were thawed on ice, resuspended in lysis buffer (50

$148 \mathrm{mM}$ Tris $\mathrm{pH} 8,500 \mathrm{mM} \mathrm{NaCl}, 10 \mathrm{mM}$ imidazole, $10 \%$ glycerol and $6 \mathrm{mM} \beta$-mercaptoethanol). 1

$149 \mathrm{mg} / \mathrm{ml} \mathrm{DNAse}$ and $0.25 \mathrm{mg} / \mathrm{ml}$ lysozyme were added during resuspension. For TAT-NMR-CaM

150 only, Halt Protease Inhibitor Cocktail (ThermoFisher) was added to 1x per manufacturer's

151 protocol. Cells were broken via passage through a French press at 20,000 psi and subjected to

152 centrifugation at $\sim 27,000 \times \mathrm{g}$ to pellet unbroken cells and debris. Clarified lysate was passed over

153 a cobalt affinity column using an FPLC system while monitoring $\mathrm{A}_{280}$, washed with wash buffer

154 (equivalent to lysis buffer with $25 \mathrm{mM}$ imidazole instead of $10 \mathrm{mM}$ ) until baseline absorbance was

155 attained, after which protein was eluted in elution buffer (lysis buffer with $250 \mathrm{mM}$ imidazole).

156 Protein-containing fractions were pooled, concentrated and exchanged by passage over a desalting

157 column into $10 \mathrm{mM}$ HEPES, pH 7.4, $150 \mathrm{mM} \mathrm{NaCl}, 10 \%$ glycerol, $1 \mathrm{mM} \mathrm{CaCl}$ for fluorescent

158 labeling, biotinylation or other further use. Quantitation was done using Bradford Assay with

159 bovine serum albumin as standard. 
Biotinylation was accomplished using NHS-LC-LC biotin, crosslinked per the manufacturer's protocol (ThermoFisher, USA). For fluorescent labeling, DyLight 650 was

162 similarly crosslinked to cargo proteins or TAT-CaM and dye removal columns were used to 163 remove unreacted dye (ThermoFisher). Stoichiometries were adjusted so that on average, less than 164 one fluorophore per protein was incorporated.

165 Biolayer interferometry. Kinetic analysis was performed on ForteBio Octet Red 96 BLI 166 biosensor (Sartorius, Goettingen, Germany) at $30^{\circ} \mathrm{C}$. All buffer used for sample dilutions and 167 assays was $10 \mathrm{mM}$ HEPES, pH 7.4, $150 \mathrm{mM} \mathrm{NaCl}, 10 \%$ glycerol, $1 \mathrm{mM} \mathrm{CaCl} 2$ 0.1\% Tween-20. 168 Biotinylated TAT-NMR-CaM was loaded onto streptavidin (SA) sensors. After establishing a 169 baseline, sensors were moved into buffer containing CBS-MBP. Association was monitored for 170300 s after which sensors were moved to buffer only for $300 \mathrm{~s}$ and then buffer containing $10 \mathrm{mM}$ 171 EDTA to monitor dissociation in the presence and absence of available $\mathrm{Ca}^{2+}$. Association and no172 EDTA dissociation were fit to a one-state simple association-then-dissociation global model to 173 determine kinetic and affinity constants. EDTA-induced dissociation was fit to a global one-state 174 exponential decay model to assign a fast-off, $\mathrm{Ca}^{2+}$ free dissociation constant. GraphPad Prism was 175 used for all analysis.

176 Cell penetration assays. Endpoint assays were performed as described [10, 11] in which

177 the CPP-adaptor/cargo complexes $(1 \mu \mathrm{M}$ each component as determined by quantitation via 178 Bradford Assay, unless noted otherwise) were incubated with cells for $1 \mathrm{~h}$ prior to imaging. For 179 endocytosis inhibition assays, cells were seeded into an 8 -well plate 20 hours prior so that $\sim 60 \%$ 180 confluency was achieved by time of imaging. Cells were pretreated for 30 min with media 181 containing $25 \mu \mathrm{M}$ Chlorpromazine hydrochloride (CPZ), $5 \mathrm{mM}$ methyl-B-cytodextrin $(\mathrm{M} \beta \mathrm{CD})$, $18250 \mu \mathrm{M}$ EIPA), 5-(N-ethyl-N-isopropyl) amiloride (EIPA) or an equal volume of solvent in the 
183 negative control sample. Inhibitor-containing media was aspirated and replaced with media

184 containing TAT-NMR-CaM/CBS-MBP complexes in which the CBS-MBP was labelled with

185 DyLight 650. After a 45 min incubation, cells were washed twice with phosphate-buffered saline

186 containing $\mathrm{Mg} 2+$ and $\mathrm{Ca} 2+$ followed by addition of imaging media (DMEM Glutamax $+10 \%$

187 FBS + 25 mM HEPES, pH. 7.4 and NucBlue stain). Cells were then imaged at $37^{\circ} \mathrm{C}$ without $\mathrm{CO}_{2}$

188 on the confocal microscope.

To allow for imaging during the exposure of cells to adaptor/cargo complexes, a real-time

191 GlutaMax media (+4.5g/L D-glucose, no sodium pyruvate) supplemented with 10\% fetal bovine

192 serum (FBS) in a T-25 culture flask. Cells were prepared 20-24 hours prior to assay by deposition

193 of approximately $4.2 \times 10^{4}$ cells into an Ibidi (Gräfelfing, Germany) $\mu$-Slide VI 0.4 channel slide,

194 which yielded approximately $70 \%$ confluency by time of assay. Media were added to channel

195 reservoirs to reach $75 \%$ capacity and cells were incubated overnight. Thirty minutes prior to

196 imaging, the channel slide was aspirated and fresh media containing NucBlue (ThermoFisher)

197 nuclear stain were delivered into the channel slide. The channel slide was transferred to an

198 incubated stage $\left(37^{\circ} \mathrm{C}\right)$ on a Zeiss LSM 900 confocal microscope. CPP-adaptor/CBS-cargo

199 complexes or analogous control proteins were pumped into tubing by peristaltic pump at 0.4

$200 \mathrm{ml} / \mathrm{min}$ using a syringe reservoir (Fig S2). Imaging with 40X Plan-Apochromat objective (N.A. =

201 0.95, M27) began as proteins flowed into channel slide. Flow of protein was halted in channel after

202 one minute and imaging continued for 40 minutes with protein present on cells during imaging

203 process. The cells were washed with $3 \mathrm{~mL}$ of DMEM GlutaMax $(+4.5 \mathrm{~g} / \mathrm{L}$ D-glucose, -sodium

204 pyruvate $)+10 \%$ FBS $+25 \mathrm{mM}$ HEPES in flow as imaging continued for 10-15 minutes. After

205 imaging was complete, 70\% ethanol was pumped through tubing to clean the system. Lasers (555 
$\mathrm{nm}$ and $405 \mathrm{~nm}$ ) were used at $0.2 \%$ power to capture labeled protein or nuclei. Pinhole size was

207 set at one Airy Unit (AU) for both lasers. The mode of collection was programmed to repeat per

208 line and intensity signatures were determined based off mean intensity values. The Definite Focus

209 feature was used continuously to maintain a consistent focus plane for image acquisition, which

210 was located at the midpoint of the cell to assure that observed cellular fluorescence was internal

211 and not surface adherent.

212 Statistics. To determine the extent of cargo diffusion throughout the interiors of cells, a

213 pairwise analysis was performed to measure distances between fluorescent pixels in micrographs

214 taken from endpoint cell penetration assays at the midpoint of cells. 50 randomly selected cells for

215 each condition were examined. Cells were outlined using ImageJ and from within those

216 boundaries, distance measurements for all pixels that exhibited fluorescence from every other such

217 pixel were measured. For computational reasons, distance pairs were randomly sampled to reach

218 a data set of $10 \%$ of the original size. Using SAS ${ }^{\circledR}$ (Cary, NC, USA), values were compiled into a

219 distance matrix and then all distances calculated were aggregated into one column, from which

220 milliles $(0.1 \%$ percentile, $0.2 \%$ percentiles, ... $100 \%$ percentiles $)$ were found and used to represent

221 the pair-wise distances of the exhibited fluorescence in one cell. The resultant sets consisted of

22250,000 points for each condition (50 cells x 1,000 milliles each) and compared in their distribution.

223 Significance for distribution between distances in control and experimental cells was determined

224 by Kolmogorov-Smirnov test [21]. 


\section{Results and discussion}

charge would result in differences in internalization and release of CBS-containing cargos, we examined numerous calmodulin sequences in the protein database. Heterocephalus glaber

231 calmodulin offered an interesting variation in size and net charge relative to human calmodulin as

232 well as what amounted to a natural spacer element consisting of residues 1-128 between the N-

233 terminal TAT sequence and the conserved calmodulin sequence (Fig 1). Residues 1-128 also

234 reduced the overall net charge by 9 relative to CaM with the addition of 16 basic residues and 7

235 acidic ones. Expression and purification were readily achieved and TAT-NMR-CaM bound the

236 calmodulin binding sequence common to all cargo proteins we have examined to date.

Fig 1. Sequence alignment of naked mole rat and human calmodulins. NMR, naked mole rat. Acidic residues are highlighted in red, basic in blue. Cysteines are highlighted in yellow. idealized cargo, maltose binding protein (MBP) was chosen because of its high stability, solubility TAT-MBP, were produced in mg quantities per batch via a one-step affinity purification.

243 solution (Fig 2A), preventing a direct determination of $\mathrm{k}_{\mathrm{d}}$ and hence $\mathrm{K}_{\mathrm{D}}$ via fit to an association-

244 then-dissociation model. Why the anomalous behavior was observed is unknown and could include

245 slowly-occurring oligomerization, binding-induced conformational changes or surface-induced

246 denaturation (a phenomenon previously observed with entirely different binding partners, [22]),

247 but it was repeatedly observed with CBS-MBP when used as either ligand or analyte. Fig 2A shows 
bioRxiv preprint doi: https://doi.org/10.1101/2021.07.23.453555; this version posted July 23, 2021. The copyright holder for this preprint (which was not certified by peer review) is the author/funder, who has granted bioRxiv a license to display the preprint in perpetuity. It is made available under aCC-BY 4.0 International license.

248 a background-subtracted sensorgram for a complete experiment in which biotinylated CBS-MBP 
bioRxiv preprint doi: https://doi.org/10.1101/2021.07.23.453555; this version posted July 23, 2021. The copyright holder for this preprint (which was not certified by peer review) is the author/funder, who has granted bioRxiv a license to display the preprint in perpetuity. It is made available under aCC-BY 4.0 International license.

249 was tethered to sensors and TAT-NMR-CaM was analyte. The partners bound rapidly (0-300s), 
bioRxiv preprint doi: https://doi.org/10.1101/2021.07.23.453555; this version posted July 23, 2021. The copyright holder for this preprint (which was not certified by peer review) is the author/funder, who has granted bioRxiv a license to display the preprint in perpetuity. It is made available under aCC-BY 4.0 International license.

250 remained tightly bound during the dissociation phase (300-1200s) and then rapidly dissociated 
bioRxiv preprint doi: https://doi.org/10.1101/2021.07.23.453555; this version posted July 23, 2021. The copyright holder for this preprint (which was not certified by peer review) is the author/funder, who has granted bioRxiv a license to display the preprint in perpetuity. It is made available under aCC-BY 4.0 International license.

251 when sensor-bound complexes were exposed to $10 \mathrm{mM}$ EDTA (1200-1500s). TAT-NMR-CaM 
bioRxiv preprint doi: https://doi.org/10.1101/2021.07.23.453555; this version posted July 23, 2021. The copyright holder for this preprint (which was not certified by peer review) is the author/funder, who has granted bioRxiv a license to display the preprint in perpetuity. It is made available under aCC-BY 4.0 International license.

252 exposed to sensors without tethered CBS-MBP evinced little signal and thus non-specific binding 
bioRxiv preprint doi: https://doi.org/10.1101/2021.07.23.453555; this version posted July 23, 2021. The copyright holder for this preprint (which was not certified by peer review) is the author/funder, who has granted bioRxiv a license to display the preprint in perpetuity. It is made available under aCC-BY 4.0 International license.

253 was negligible (data not shown). Fortunately, the association phase fit reasonably well to one-state 
exponential models (Fig 2B), allowing determination of $\mathrm{k}_{\mathrm{obs}}$ for each analyte concentration. A plot

255 of $\mathrm{k}_{\mathrm{obs}}$ vs analyte concentration [23] (Fig 2C) was not ideally linear, but regression analysis

Fig 2. BLI analysis of TAT-NMR-CaM/CBS-MBP binding. A, sensorgram of association (0300s), dissociation (300-1200s) and dissociation in $10 \mathrm{mM}$ EDTA (1200-1500s) of sensortethered CBS-MBP binding to analyte TAT-NMR-CaM in which the association phase concentration was $1000 \mathrm{nM}$ (red), $500 \mathrm{nM}$ (orange), $250 \mathrm{nM}$ (yellow), $125 \mathrm{nM}$ (green), $63 \mathrm{nM}$ (blue), $31 \mathrm{nM}$ (magenta) and $16 \mathrm{nM}$ (black). Data shown are reference subtracted against a sensor loaded with CBS-MBP run in parallel against buffer-only wells, including EDTA. B, Association phase from A fit to a single-state binding model. Raw data are colored points and fits are shown as black lines. $\mathrm{C}, \mathrm{k}_{\mathrm{obs}}$ extracted from fits to B plotted against analyte concentration from which $\mathrm{k}_{\mathrm{a}}$ and $\mathrm{k}_{\mathrm{d}}$ were determined by slope and $\mathrm{y}$-intercept, respectively. D, EDTA dissociation normalized to the start of the phase fit to a global single-state model.

256 produced an $\mathrm{R}^{2}$ of 0.95 . Extracting $\mathrm{k}_{\mathrm{on}}$ (slope) and $\mathrm{k}_{\mathrm{off}}\left(\mathrm{y}\right.$-intercept) yielded constants of $9.1 \times 10^{3}$

$257 \mathrm{M}^{-1} \mathrm{~s}^{-1}$ and $4.8 \times 10-4 \mathrm{~s}^{-1}$, respectively. The resultant $\mathrm{K}_{\mathrm{D}}$ is $53 \mathrm{nM}$. When the beginning of the

258 EDTA dissociation phase was normalized to $0 \mathrm{~nm}$ shift at time 0 , the resultant dissociation curves

259 fit a global one-state exponential decay model with $\mathrm{k}_{\mathrm{d}} 0.02 \mathrm{~s}^{-1}$. Because of the anomalous behavior

260 observed, the constants as determined should not be considered rigorous kinetic assignments

261 because they are the result of simple one-state analyses of complex events, but can be compared

262 with those previously determined for TAT-CaM and other CPP-EF hand adaptor proteins with

263 other cargos $[10,11]$. TAT-NMR-CaM/CBS-MBP parameters fall within the range of those

264 observed for the other adaptor and cargo pairs. Thus it can be concluded that while nonideality in

265 the data results from complex binding behavior whether biologically relevant or an artifact of the

266 method, it is a small fraction of the signal observed, the constants are representative of the major

267 binding events and show that TAT-NMR-CaM binds CBS-cargos with similar kinetics to other

268 CPP-adaptor constructs, which is unsurprising because the NMR CaM domain is effectively

269 invariant from the human constructs previously measured, i.e. residues 1-128 make no difference

270 in the CaM-CBS affinity. 

effectively delivering CBS-MBP cargos and evincing more diffuse subcellular distribution that TAT-MBP, a control protein analogous to the standard CPP-cargo linkages. (Fig 3A \& B).

274 Interestingly, CaM with no CPP in complex with CBS-MBP moiety evinced even lower 275 background that CBS-MBP alone (Fig 3C). of its overall less acidic character and separation in primary sequence of the TAT moiety and the

279 calmodulin domain. In a future study, we intend to more thoroughly examine calmodulins from other species that have even more divergent character such as a net positive charge for their utility

281 as CPP-adaptors.

Real-time assay development. The vast majority of cell-penetration assays in the

Fig 3. TAT-NMR-CaM cell-penetration assay. A, control with $400 \mathrm{nM}$ CBS-MBP only and B, TAT-NMR-CaM/CBS-MBP (400 nM each) added to BHK cells; CBS-MBP was labelled (rendered as yellow) and cell nuclei (white) were stained prior to imaging with NucBlue. Cells were imaged with $40 \mathrm{X}$ objective at mid-point depth in cell and scale bar $=20 \mu \mathrm{m}$.

283 literature are endpoint assays either with fixed samples or in live cells, in which CPP-cargos are

284 incubated with cells prior to imaging, usually an hour or even longer, leaving open the question of

285 the speed at which entry and endosomal escape occur. Previous efforts from our group to examine

286 delivery at short time points were unable to reduce cargo-addition-to-imaging time to under fifteen

287 minutes by which time cargos were diffusely distributed about the cells [24]. Thus, it was very

288 desirable to develop a real-time assay where cargo delivery could be observed ab initio. Because

289 they exhibited traits that made them an improved CPP-adaptor and cargo pair, TAT-NMR-CaM

290 and CBS-MBP were used to develop a real-time cell penetration assay. As shown in the Supporting

291 Information, a flow system installed on an incubated confocal stage was built (S1 Fig). CPP- 
adaptor/CBS-cargo complexes could be delivered to a sample while imaging, allowing observation

293 of cell penetration from time zero. BHK cells in channel slides on an incubated confocal stage

294 were supplied with media containing adaptor cargo complexes via tubing connected to inlet and

295 outlet points. Flow was controlled by a peristaltic pump upstream of the slide and media containing

296 adaptors and cargos were kept in an upstream syringe reservoir until pumped.

After successful development and parameterization, the assay confirmed that TAT-NMR-

CaM-based CPP-mediated delivery is rapid, with cytosolic delivery being observable in under

Fig 4. Gallery of images from real-time delivery of CBS-MBP to live cells. Top panel, TATNMR-CaM/CBS-MBP (400 nM each) were delivered; Bottom panel, CBS-MBP (400 nM) only was delivered. CBS-MBP was labelled (rendered as yellow) and cell nuclei (white) were stained prior to imaging with NucBlue. Cells were imaged with $40 \mathrm{X}$ objective at mid-point depth in cell. Scale bar $=20 \mu \mathrm{m}$. . CBS-MBP was present in the media throughout this imaging process. Movies available in Supporting Information.

ten minutes (Fig 4A). Real-time videos of the assays are available in Supporting Information and

show noticeable delivery within seven minutes, a substantially shorter time-to-cytoplasm than

301 prior assays allow detection. Parallel controls exhibited very little fluorescence, consistent with

302 the labelled cargo not being delivered into cells (Fig 4B).

304 fluorescence exhibited an increase over time that approximated linearity to the extent the assay

305 was sensitive enough to determine (Fig 5). The few other studies in the literature to attempt

306 observation at less than 30 minute time points found non-linearity, e.g. $[17,25]$, that is open to

307 interpretation but may represent the attainment of equilibrium or saturation of receptors due to

308 slow-off kinetics. Our results are not in conflict with prior findings for numerous reasons including

309 that they are entirely different constructs. Additionally, our CPP-adaptor system is able to deliver

310 cargos at lower concentrations, in this case $400 \mathrm{nM}$, as compared to commonly used 1-10 $\mu \mathrm{M}$ in 
311 other studies. Thus, we may be observing the CPP uptake equivalent of pseudo-first order kinetics

312 while other studies have observed more complex phenomena related to higher CPP concentrations.

Fig. 5. Quantitation of internal cellular fluorescence as a function of time. Backgroundsubtracted fluorescence as a function of time. Intensities are the average of three separate experiments. Error bars represent S.E.M.

313 While the ultimate assay can be readily executed in a single trial, it did not arise without

314 many iterations. Winston Churchill once said, "success consists of going from failure to failure

315 without loss of enthusiasm." Accordingly, we conducted a great deal of enthusiastic trying and

316 failing prior to arriving at a workable protocol. Cell stress caused by shear stress and pH variance

317 due to the restrictive geometry was problematic. Complex delivery was originally accomplished

318 by gravity flow from a syringe suspended above the stage, a peristaltic pump was added to control

319 flow rate and reduce shear stress. Though done in an incubator system on the stage, concerns about

320 lack of control of $\mathrm{CO}_{2}$ concentrations in the flow system resulted in addition of HEPES to the

321 media to buffer. These changes results in improvements of cell health as observed by morphology

322 and the lack of compromised cells appearing to take up fluorophores in all conditions.

323 Photobleaching from repeated imaging of cells in the same field, a common problem in real-time

324 imaging $[26,27]$ was observed in preliminary experiments. Images from separate areas of the slide

325 that had not been exposed to repeated excitation evinced greater fluorescence than the area subject

326 to repeated imaging. Photobleaching is thus a source of error in quantitation, but has the effect of

327 lower observable mean fluorescence and thus a resultant undermeasurement of delivered cargo. 
A pulse-chase style delivery experiment was performed to follow the fate of delivered cargo. $400 \mathrm{nM}$ TAT-NMR-CaM/CBS-MBP complexes were delivered to cells and left in the chamber for ten minutes after which fresh media not containing adaptor-cargo complexes were pumped into the chamber to flush out undelivered adaptor-cargos. As expected, mean fluorescence rose quickly, peaking at 15 minutes (Fig 6). Later timepoints showed no significant decline in

333 fluorescence, indicating that delivered cargo remained within the cell. The distribution of 334 fluorescence likewise suggests that it is largely cytoplasmic, indicating that delivered cargo was 335 not rapidly degraded or recycled to the surface.

Fig 6. Pulse-chase cell-penetration assay. Quantification of Pulse Chase CPP Mediated Cargo Delivery in BHK21 Cells. WT TAT-NMRCaM and CBS-MBP were delivered at a concentration of $400 \mathrm{nM}$ for 10 minutes. Experiments completed to $\mathrm{N}=3$. Mean intensity values were averaged across all three movies. Errors bars were calculated from Standard Error of the Mean for each timepoint and were averaged across all three movies. Quantification performed using Fiji (ImageJ) software. Intracellular fluorescent signal was calculated and subtracted from extracellular background signal present at each timepoint. The red line is meant to be an aid for the eyes and does not indicate any fit to the data. Error bars represent S.E.M. for each timepoint.

The TAT-CaM architecture was developed to enhance endosomal escape by post-

338 endocytic dissociation of cargo from CPP. To quantify the difference between it and a standard

339 CPP-cargo linkage in efficiency of cargo distribution throughout the cell, endpoint assays of MBP

340 delivered as CBS-fused cargo via TAT-NMR-CaM or covalently conjugated to TAT ("TAT-

341 MBP") were performed. With the hypothesis that endosomally trapped cargos would exhibit a

342 more punctate distribution and therefore have a distribution that evinced shorter overall distances,

Fig 7. Distance analysis. A, TAT-MBP only and B, TAT-NMRCaM/CBS-MBP) complexes are representative images . C, distribution of (Blue) TAT-MBP and (Red) TAT-NMRCaM + CBS-MBP pairwise distances of fluorescent pixels are compared using the KolmogorovSmirnov Test for significance. Analysis completed using SAS ${ }^{\circledR}$ Studio software. Data set 10\% of original size and values of " 0 " removed. X-axis = distance values where adjacent pixels have a distance value of 1 . Y-axis $=$ proportion of values, e.g. proportion of $0.4=40$ th percentile of data set. 
343 each fluorescent pixel was measured with respect to all other fluorescent pixels within a cell.

344 Representative micrographs for TAT-MBP and CBS-MBP delivered via TAT-NMR-CaM are

345 shown in Fig 6A and B, respectively. Distributions of distances are shown in Fig 7C. As expected,

346 the distances between pixels in cells with delivered CBS-MBP were longer than TAT-MBP,

347 indicating broader cytosolic distribution. A Kolmogorov-Smirnov test showed significant

348 difference $(\mathrm{p}$-value $<.0001)$. Distance analysis was not performed for other experiments in this

349 study due to resource limitations, but we observed analogous punctate localization versus wider,

350 presumably cytoplasmic, dispersion with TAT-myoglobin and TAT-CaM/CBS-myoglobin, a

351 model cargo used in prior studies (data not shown). We hope to develop an automated analysis in

352 a future study.

353 To examine the potential mechanism of endocytosis, several small molecule inhibitors

354 were applied to cells prior to delivery of TAT-NMR-CaM/CBS-MBP complexes. Chlorpromazine

355 hydrochloride (CPZ), methyl- $\beta$-cytodextrin $(\mathrm{M} \beta \mathrm{CD})$ and 5-(N-ethyl-N-isopropyl) amiloride

356 (EIPA), inhibitors of clathrin-mediated endocytosis, caveolae-mediated endocytosis (CvME) and

357 micropinocytosis, respectively, were used in cell penetration assays at concentrations previously

358 shown to inhibit delivery of other CPP-cargos [28-30] (Fig 8). In the presence of CPZ, protein

359 uptake did not appear to change significantly. In some cells, small differences such as the presence

360 of larger fluorescent endosomes can be observed. Similar effects were seen in cells that were

361 inhibited by EIPA. It is thus possible that these inhibitors were able to decrease overall protein

Fig 8. Cell-penetration assays in the presence of inhibitors of endocytosis. WT TAT-NMRCaM (1uM) and CBS-MBP (1uM) delivered to BHK21 cells in endpoint static assay $(\mathrm{N}=3)$. Cell nuclei (blue) stained with NucBlue and CBS-MBP (red) labeled with DyLight 650. Cells pretreated with inhibitor for 30 minutes. Proteins introduced to cells in presence of inhibitor. (A) No inhibitor. (B) Chlorpromazine Hydrochloride mediated inhibition of CME. (C) Methyl- $\beta$ cyclodextrin mediated inhibition of CvME. (D) 5-(N-Ethyl-N-isopropyl) amiloride mediated inhibition of MP. Cells imaged with $40 \mathrm{X}$ objective and scale bar $=20 \mu \mathrm{m}$. Red intensity values increased to 45,000 on histogram in Zen Software to improve visualization of uptake. 
uptake and slow endocytic trafficking during delivery, but no concrete conclusions can be made on the effectiveness of these inhibitors in reducing delivery. in confocal images. Additionally, cells appeared to have an increased level of labeled protein adhered to the membrane surface of the cell, suggesting the possibility of reduced delivery, but there are several caveats to consider when making such inferences. First, the concentration of $\mathrm{M} \beta \mathrm{CD}$ used to inhibit CvME was very high, which could lead to other cellular changes, indirectly reducing total protein uptake. Second, due to the lower solubility of this compound, a sizable amount (10\%) of $\mathrm{H}_{2} \mathrm{O}$ (solvent) was present as cells were inhibited with $\mathrm{M} \beta \mathrm{CD}$. It is possible that

371 this change in environment could cause cells to have an altered uptake efficiency and total uptake

372 level. Lastly, it is possible that the inhibitor used was unspecific and therefore was affecting other

373 pathways in addition to CvME. With these factors in mind, no definite conclusions can be made

374 with regard to TAT-NMR-CaM-mediated delivery, though an optimistic speculation could be that

375 delivery is so efficient that it remains relatively unaffected at inhibitor concentrations that are

376 known to affect other CPP-cargos.

While confident that the assay can be iteratively improved and analysis automated and made more user-friendly in time, we have chosen to publish the work in present form in the hopes that it will be of use to the field. The assay is relatively facile and while requiring a confocal microscope, otherwise consist of commercially available chamber slides, a peristaltic pump and

381 everyday tubing and a syringe. Using the assay, it was demonstrated that our CPP-adaptor 382 delivered a protein cargo within minutes, that delivery under the conditions examined was linear 383 in rate and that the CaM-CBS linkage effected more diffuse cellular distribution of cargo than an 384 analogous covalently linked cargo, consistent with more effective endosomal escape. Further, the 
385 adaptor based on calmodulin from Heterocephalus glaber is an improvement upon the previously

386 described TAT-CaM and suggests that further improvements in efficiency and perhaps boarder

387 utility with respect to cargo-specific requirements can be engineered by modulating the

388 physicochemical characterists of the CPP-adaptor including charge and distance between the CPP

389 moiety and the EF hand domain, among other possibilities. Future studies will examine these

390 issues as well as the parameters of delivery and mechanism of entry.

\section{References}

397 medical and biological applications. Adv Drug Deliv Rev. 2009;61:953-64.

398 2. Johnson RM, Harrison SD, Maclean D. Therapeutic applications of cell-penetrating peptides.

399 Methods Mol Biol 2011;683:535-51.

400 3. Lonn P, Dowdy SF. Cationic PTD/CPP-mediated macromolecular delivery: charging into the 401 cell. Expert Opin Drug Deliv. 2015;26:1-10.

402 4. Derakhshankhah H, Jafari S. Cell penetrating peptides: A concise review with emphasis on 403 biomedical applications. Biomed Pharmacother. 2018;108:1090-6.

404 5. Glogau R, Blitzer A, Brandt F, Kane M, Monheit GD, Waugh JM. Results of a randomized, 405 double-blind, placebo-controlled study to evaluate the efficacy and safety of a botulinum toxin 
type A topical gel for the treatment of moderate-to-severe lateral canthal lines. J Drugs Dermatol. 2012;11(1):38-45.

408 6. Lecher JC, Nowak SJ, McMurry JL. Breaking in and busting out: Cell-penetrating peptides and

409 the endosomal escape problem. Biomol Concepts. 2017;8(3-4):131-41.

410 7. Xie J, Bi Y, Zhang H, Dong S, Teng L, Lee RJ, et al. Cell-Penetrating Peptides in Diagnosis

411 and Treatment of Human Diseases: From Preclinical Research to Clinical Application. Front

$412 \quad$ Pharmcol. 2020;11:697.

413 8. Habault J, Poyet J-L. Recent Advances in Cell Penetrating Peptide-Based Anticancer Therapies.

414 Molecules. 2019;24(5):927.

415 9. Bolhassani A, Jafarzade BS, Mardani G. In vitro and in vivo delivery of therapeutic proteins 416 using cell penetrating peptides. Peptides. 2017;87:50-63.

417 10. Salerno JC, Ngwa VM, Nowak SJ, Chrestensen CA, Healey AN, McMurry JL. Novel cell 418 penetrating peptides effect intracellular delivery and endosomal escape of desired protein cargos. 419 J Cell Sci. 2016;129(5):893-7.

420 11. Ngwa VM, Axford DS, Healey AN, Nowak SJ, Chrestensen CA, McMurry JL. A versatile 421 cell-penetrating peptide-adaptor system for efficient delivery of molecular cargos to subcellular 422 destinations. PloS one. 2017;12(5):e0178648.

423 12. Pooga M, Hällbrink M, Zorko M, Langel U. Cell penetration by transportan. FASEB J. $424 \quad 1998 ; 12(1): 67-77$.

425 13. Drin G, Cottin S, Blanc E, Rees AR, Temsamani J. Studies on the Internalization Mechanism 426 of Cationic Cell-penetrating Peptides*. J. Biol. Chem. 2003;278(33):31192-201.

427 14. Richard JP, Melikov K, Vives E, Ramos C, Verbeure B, Gait MJ, et al. Cell-penetrating 428 peptides A reevaluation of the mechanism of cellular uptake. J. Biol. Chem. 2003;278(1):585-90. 

internalization mechanisms among arginine-rich peptides. J. Biol. Chem 2002;277(4):2437-43.

432 Characterisation of cell-penetrating peptide-mediated peptide delivery. Br J Pharmacol. $433 \quad 2005 ; 145(8): 1093-102$.

434 17. Mäger I, Eiríksdóttir E, Langel K, El Andaloussi S, Langel U. Assessing the uptake kinetics 435 and internalization mechanisms of cell-penetrating peptides using a quenched fluorescence assay. 436 Biochim. Biophys. Acta. 2010;1798(3):338-43.

437 18. Christensen MV, Kongstad KT, Sondergaard TE, Staerk D, Nielsen HM, Franzyk H, et al. ${ }^{19}$ F438 substituted amino acids as an alternative to fluorophore labels: monitoring of degradation and 439 cellular uptake of analogues of penetratin by ${ }^{19}$ F NMR. J. Biomol NMR. 2019;73(3-4):167-82.

440 19. Kim H, Um E, Cho SR, Jung C, Kim H, Kim JS. Surrogate reporters for enrichment of cells 441 with nuclease-induced mutations. Nat Methods. 2011;8(11):941-3.

442 20. McMurry JL, Minamino T, Furukawa Y, Francis JW, Hill SA, Helms KA, et al. Weak 443 Interactions between Salmonella enterica FlhB and Other Flagellar Export Apparatus Proteins 444 Govern Type III Secretion Dynamics. PLOS ONE. 2015;10(8):e0134884.

445 21. Feller W. On the Kolmogorov-Smirnov Limit Theorems for Empirical Distributions. Ann Math 446 Stat. 1948;19(2):177-89.

447 22. McMurry JL, Chrestensen CA, Scott IM, Lee EW, Rahn AM, Johansen AM, et al. Rate, affinity 448 and calcium dependence of CaM binding to eNOS and nNOS: effects of phosphorylation. FEBS 449 J. 2011;278(24):4943-54.

450 23. Goodrich JA, Kugel JF. Rate Constants for Binding and Dissociation. In: Binding and Kinetics 451 for Molecular Biologists. Cold Spring Harbor, NY: Cold Spring Harbor Press; 2007. p. 69-97. 
453 Cargos into Living Cells. Master's Thesis, Kennesaw State University. 2016. Available from

454 https://digitalcommons.kennesaw.edu/mscs_etd/10/

455 25. Brock DJ, Kustigian L, Jiang M, Graham K, Wang TY, Erazo-Oliveras A, et al. Efficient cell 456 delivery mediated by lipid-specific endosomal escape of supercharged branched peptides. Traffic.

$457 \quad 2018 ; 19(6): 421-35$.

458 26. Sung MH, McNally JG. Live cell imaging and systems biology. Wiley Interdiscip Rev Syst 459 Biol Med. 2011;3(2):167-82.

460 27. Magidson V, Khodjakov A. Circumventing photodamage in live-cell microscopy. Methods $461 \quad$ Cell Biol. 2013;114:545-60.

462 28. Francia V, Reker-Smit C, Boel G, Salvati A. Limits and challenges in using transport inhibitors 463 to characterize how nano-sized drug carriers enter cells. Nanomedicine. 2019;14(12):1533-49.

464 29. Young Kim H, Young Yum S, Jang G, Ahn DR. Discovery of a non-cationic cell penetrating 465 peptide derived from membrane-interacting human proteins and its potential as a protein delivery $466 \quad$ carrier. Sci Rep. 2015;5:11719.

467 30. Rezgui R, Blumer K, Yeoh-Tan G, Trexler AJ, Magzoub M. Precise quantification of cellular 468 uptake of cell-penetrating peptides using fluorescence-activated cell sorting and fluorescence 469 correlation spectroscopy. Biochim Biophys Acta. 2016;1858(7 Pt A):1499-506.

\section{Supporting information}

471 S1. Descriptions of plasmids and proteins encoded thereby.

472 S2. Fig. Real-time imaging assay set-up on Zeiss LSM 900 confocal microscope. A, overview of 473 tubing system set up from outside of incubator case. B, channel slide attached to tubing system, 474 sitting above 40X objective. C, left side view of channel slide and tubing set up. Tubing is inserted 
475 through the back of the incubator and run around the back side of the microscope. D, right side

476 view of channel slide and tubing set up. Tubing runs from reservoir, through the back of the

477 incubator case, and up to the peristaltic pump. Tubing runs through the pump and comes back

478 through the back side of the incubator where it is run around the back of the microscope to the left

479 side of channel. Right side of channel runs via tubing to waste.

480 S3-S6. Movies of real-time assays. S3 and S4, Parts 1 and 2 of real-time assay displayed in Fig 4

481 with CBS-MBP delivered in complex with TAT-NMR-CaM; S5 and S6. Parts 1 and 2 of real-time

482 assay control of CBS-MBP delivered without TAT-NMR-CaM. 
Fig 3 


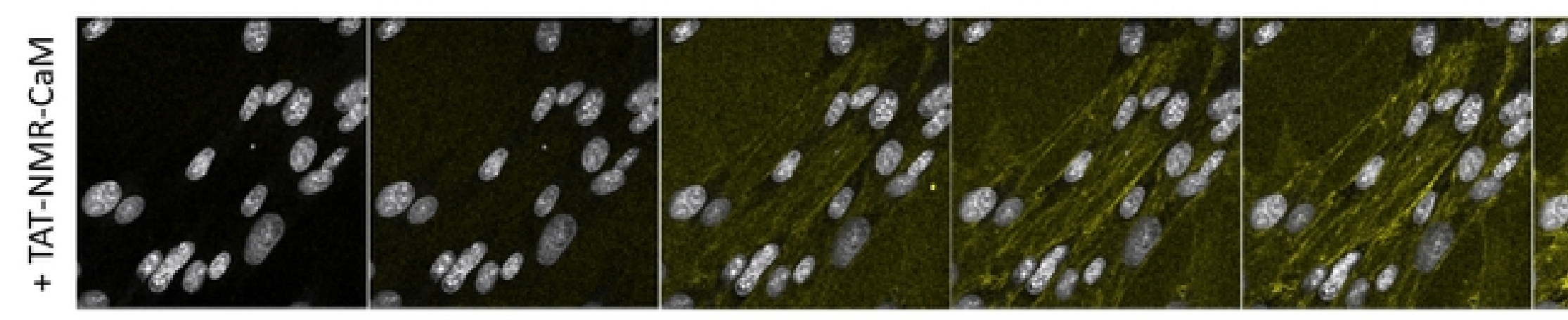

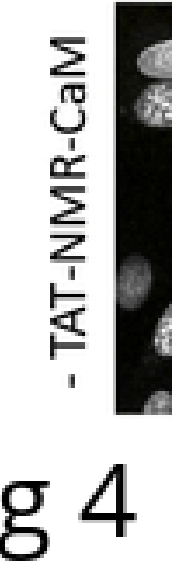

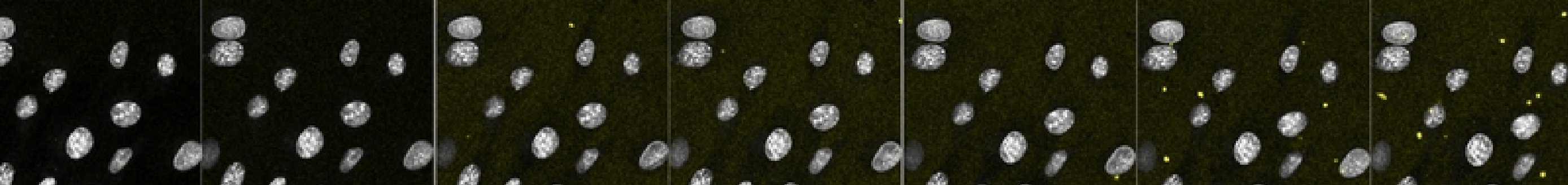

Fig 4 


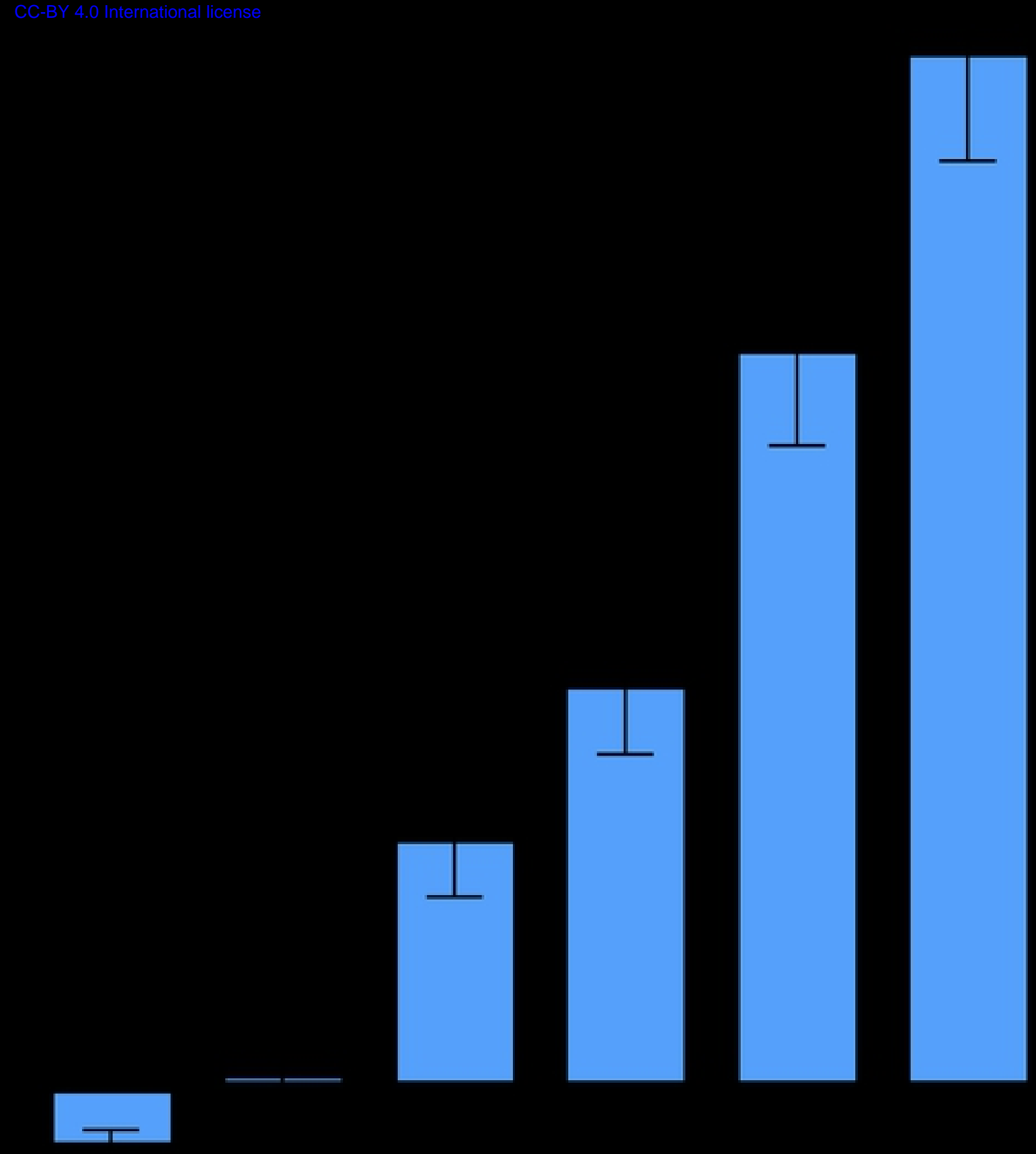

Fig 5 


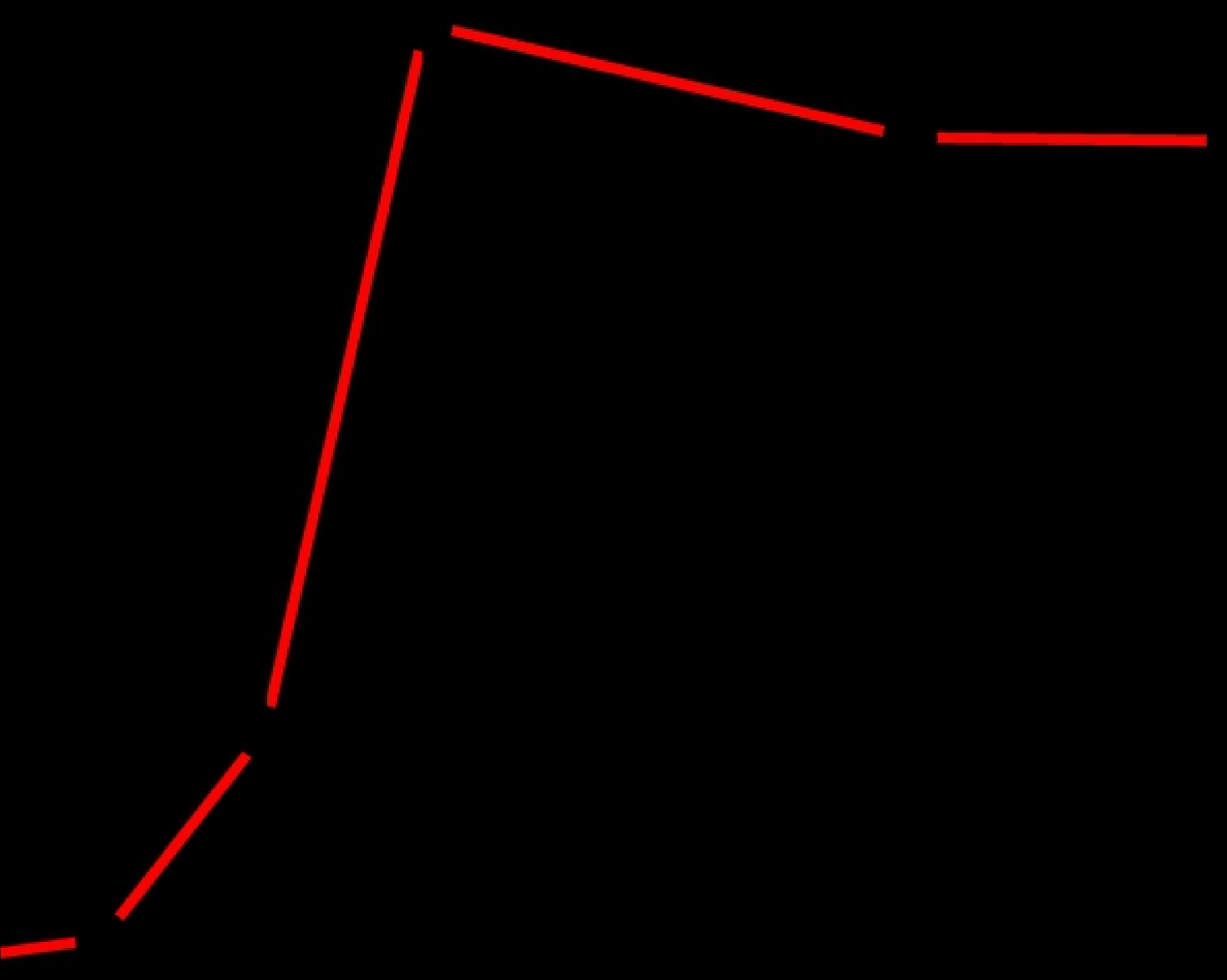

Fig 6 
R

E $\mathrm{RR}$

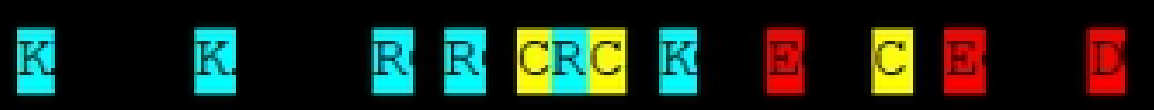

回

I늘 II

$\frac{\mathrm{RK}}{\mathrm{RK}} \mathrm{R}$

I

III

III

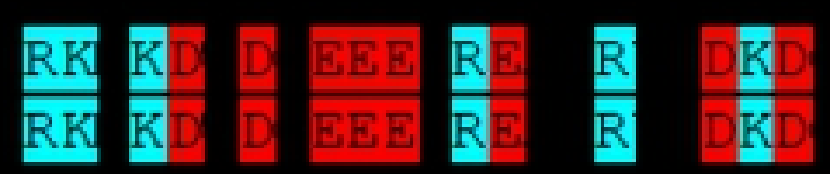

胃

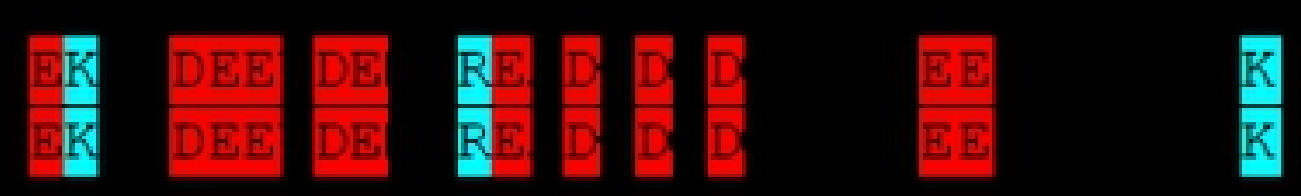

Fig 1 

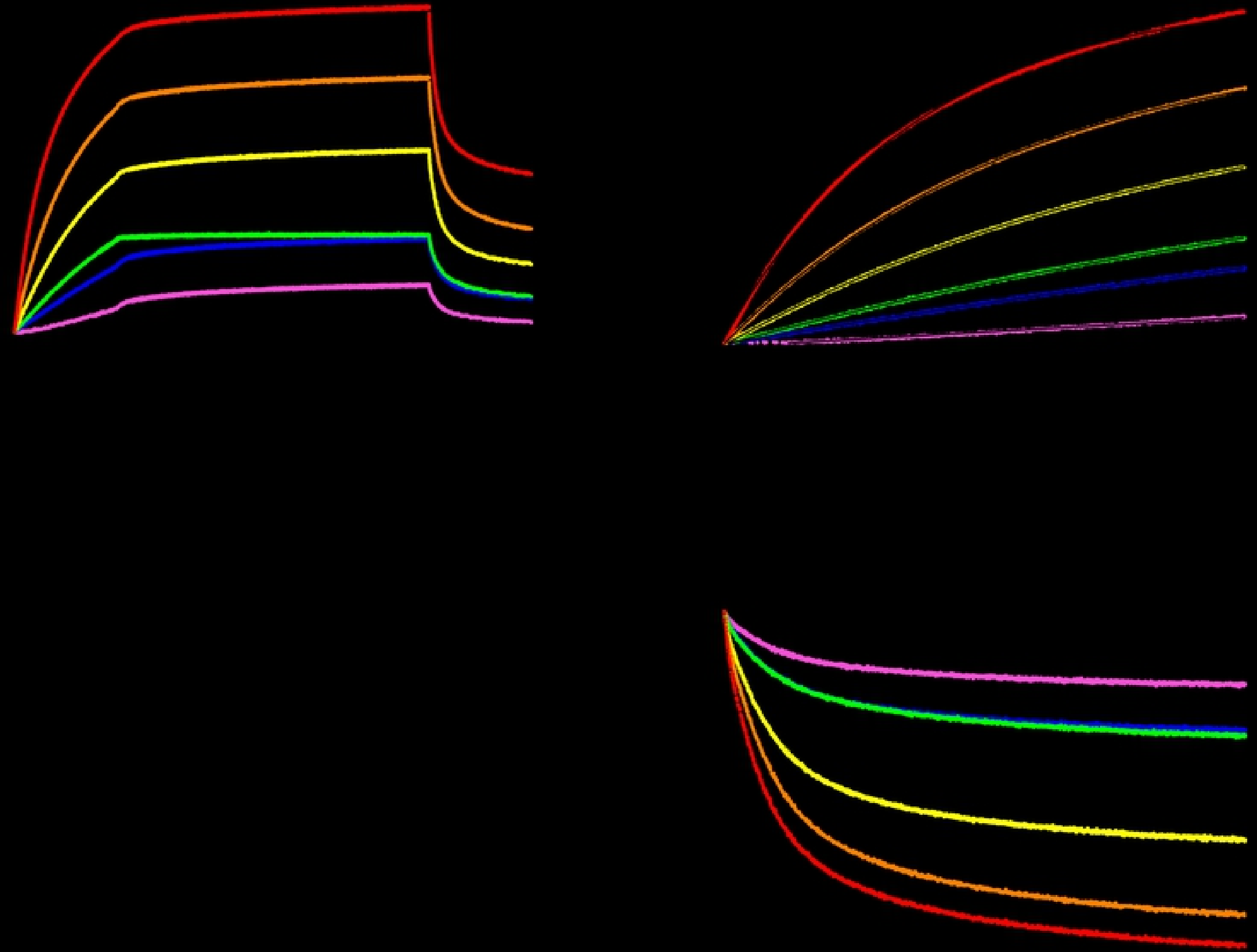

Fig 2 


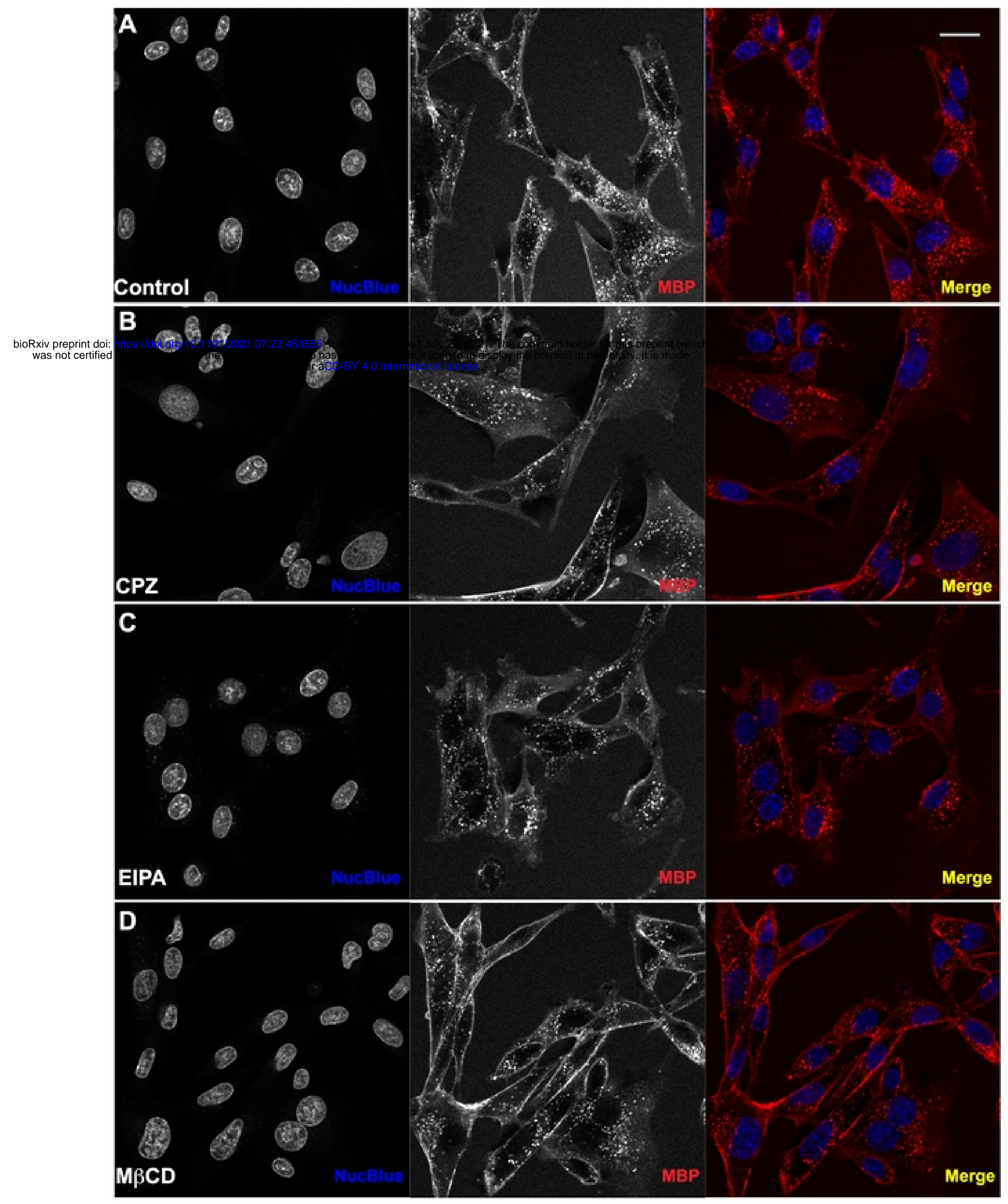

Fig 8 

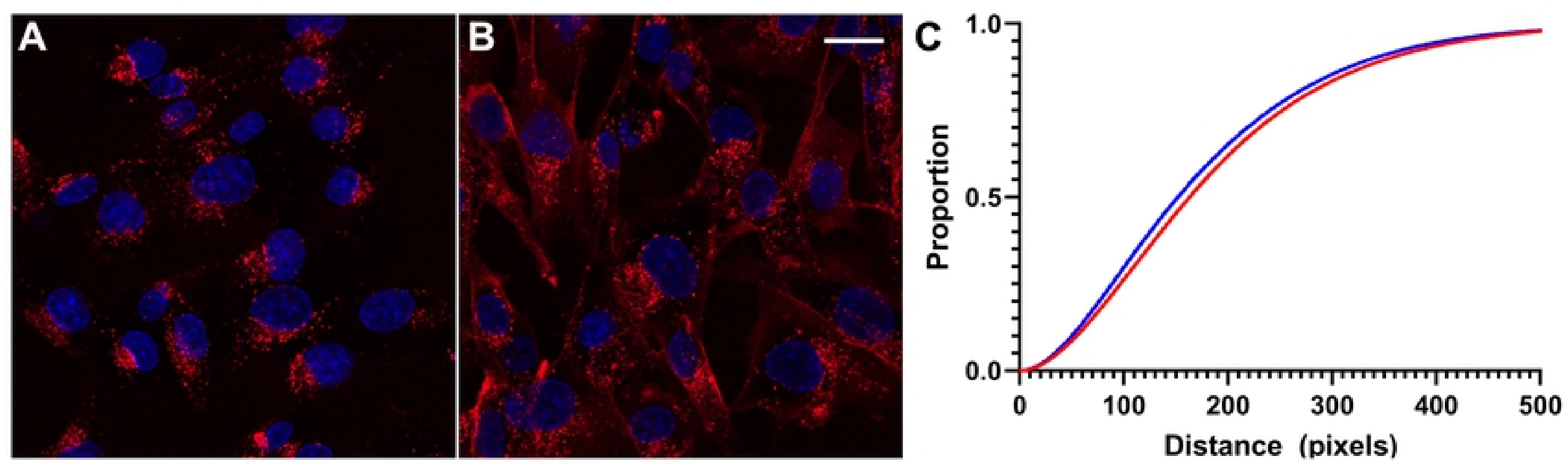

Fig 7 